\title{
Ant Colony Algorithm Applied to Power Transformer Optimization
}

\author{
Montasser Fouzaï ${ }^{1}$ \\ Department of Electrical Engineering \\ High School of Sciences and Techniques of Tunis \\ Research Unit SICISI -Tunis,Tunisia \\ fouzai.montasser@gmail.com
}

\author{
Taoufik Zouaghi ${ }^{2}$ \\ Department of Electro mechanics \\ Military Academy of Funduk Jedid \\ Tunis, Tunisia \\ zouaghitaoufik@yahoo.fr
}

\begin{abstract}
This paper describes a new optimization method based on Ant colony Algorithm for the optimal choice of the number of turns in the primary winding, flux and current density in power transformers.The goal of the proposed Algorithm is to minimize the cost of the transformer. The advantage of this method for designers is to have quick results without having to deal with all possible combinations to get the optimal solution. The proposed optimization methodology has been implemented successfully to optimize the design of power transformers and results have been compared with conventional design techniques.
\end{abstract}

Keywords - Ant colony optimization (ACO), Power Transformer Design, Power Transformer Optimization

\section{INTRODUCTION}

$\mathrm{T}$ HE objective of the optimum transformer design is to find a transformer that satisfies the technical specifications requested by the customer with lowest cost.

A conventional transformer design procedure is as follows, the engineer input data include the apparent power per phase, the leakage reactance $X$, the primary and secondary voltages $\mathrm{V} 1$ and V2 (per phase), and the frequency f, of the two winding three-legged three-phase transformer needed to be designed, and then adjusts the number of turns of the primary winding, the magnetic flux and the current density to get the electromagnetic, geometric and economic models. Then this procedure is repeated a sufficient number of times until the best results are obtained. The result can then be refined by other techniques, such as finite element method (FEM). However, the weakness of this procedure is the extremely large time consumption to achieve the best solution.

Hence, the proposed design approach has been optimized with a Multilevel Ant Colony Algorithm and the time process is significantly reduced.

The following paragraphs deal respectively, with the conventional design technique, the proposed optimization method based on Ant colony Algorithm and finally, the comparison of the two methods and a conclusion.

\section{CONVENTIONAL TRANSFORMER DESIGN OPTIMIZATION METHOD:}

The design methodology is formulated as follows:
Minimize an objective function: Total cost (transformer purchasing cost plus transformer energy loss cost).

The technical specifications requested by the customer must at least contain the apparent power per phase (St), compound primary voltage (U1), frequency (f) and finally the percent reactance $(\mathrm{X})$. Several constraints are imposed as a constant abundance of iron and copper and isolation distances.

There are three design variables:

-The number of turns of the primary winding N1,

-The magnetic Density B,

-The Current Density J,

\section{A. Methodology}

The design methodology of the two-winding three- legged, three-phase transformer can be decomposed into different models more or less independent. Four models have been defined, firstly, the calculations of electromagnetic model (primary winding reactance, form factor, magnetomotive force), secondly, the Geometric model, thirdly, the losses model and finally the economic model which purpose is to calculate the cost of the transformer (the transformer purchasing cost and the loss cost). Other models could be further integrated, such as the thermal model of the transformer.

\section{Transformer Electromagnetic model}

Among the parameters of the electromagnetic calculation models, the reactance of the primary winding is determined. The value of this reactance can be easily expressed by equation (1):

$\mathrm{X}_{2}=\mu_{0} \pi \mathrm{D}_{\mathrm{m}} \mathrm{N}_{1}^{2}(2 \pi f) \mathrm{F}_{\mathrm{f}}$

Where the form factor defining the reactance is given by equation (2)

$F_{f}=\frac{\left(D_{2}+\frac{A+G}{3}\right)}{h}$

The total primary magnetomotive force can be described as given by equation (3):

$\mathrm{mmf}=\frac{\mathrm{N}_{1} \mathrm{~S}}{\mathrm{~V}_{1}}=\mathrm{AhF}_{1} \mathrm{~J}$ 


\section{Transformer Geometric model}

The thickness of the primary and secondary winding A and G is marked on figure 1, and can be found from equations (4) and (5):

$$
\begin{aligned}
& A=\frac{N_{1} S}{V_{1} h_{1} J} \\
& G=\frac{N_{1} S}{V_{1} h_{2} J}
\end{aligned}
$$

Combining these equations, gives

$$
\mathrm{X}_{2}=\frac{\mu_{0} \pi \mathrm{D}_{\mathrm{m}} \mathrm{N}_{1}^{2}(2 \pi \mathrm{f})}{\mathrm{h}}\left[\mathrm{D}_{2}+\left(\frac{1}{\mathrm{~F}_{1}}+\frac{1}{\mathrm{~F}_{2}}\right) \mathrm{N}_{1} \mathrm{~S} / \mathrm{V}_{1} \mathrm{hJ}\right]
$$

Considering the leg diameter, the mean winding diameter is approximated as follows:

$\mathrm{D}_{\mathrm{m}}=\mathrm{L}_{\mathrm{D}}+2 \mathrm{D}_{1}+2 \mathrm{~A}+\mathrm{D}_{2}$

The leg cross section area is given by the following equation,

$$
A_{L}=\frac{\sqrt{2} V_{1}}{2 \pi f B_{T} N_{1} F_{1}}=\frac{\pi}{4} L_{D}^{2}
$$

The leg diameter is given by equation (9)

$$
\mathrm{L}_{\mathrm{D}}=\left[\frac{2 \sqrt{2} \mathrm{~V}_{1}}{\pi^{2} \mathrm{fB}_{\mathrm{T}} \mathrm{N}_{1} \mathrm{~F}_{1}}\right]^{1 / 2}
$$

The mean diameter of the winding could be expressed as follows :

$$
\mathrm{D}_{\mathrm{m}}=\mathrm{k}_{1}+\frac{\mathrm{k}_{2}}{\mathrm{~h}}
$$

Where

$$
\begin{aligned}
\mathrm{k}_{1} & =\mathrm{L}_{\mathrm{D}}+2 \mathrm{D}_{1}+\mathrm{D}_{2} \\
\mathrm{k}_{2} & =\mathrm{N}_{1} \mathrm{~S} / \mathrm{V}_{1} \mathrm{~F}_{1} \mathrm{~J} \\
\mathrm{k}_{3} & =\left(\frac{1}{\mathrm{~F}_{1}}+\frac{1}{\mathrm{~F}_{2}}\right) \frac{\mathrm{N}_{1} \mathrm{~S}}{3 \mathrm{~V}_{1} \mathrm{~J}} \\
\mathrm{k}_{4} & =\frac{\mu_{0} \pi \mathrm{N}_{1}^{2}}{\mathrm{X}_{2}}(2 \pi \mathrm{f})
\end{aligned}
$$

From (15) we can approximate the coil height

$$
h^{3}-k_{1} k_{4} D_{2} h^{2}-k_{4}\left(k_{2} D_{2}+k_{1} k_{3}\right) h-k_{2} k_{3} k_{4}=0
$$

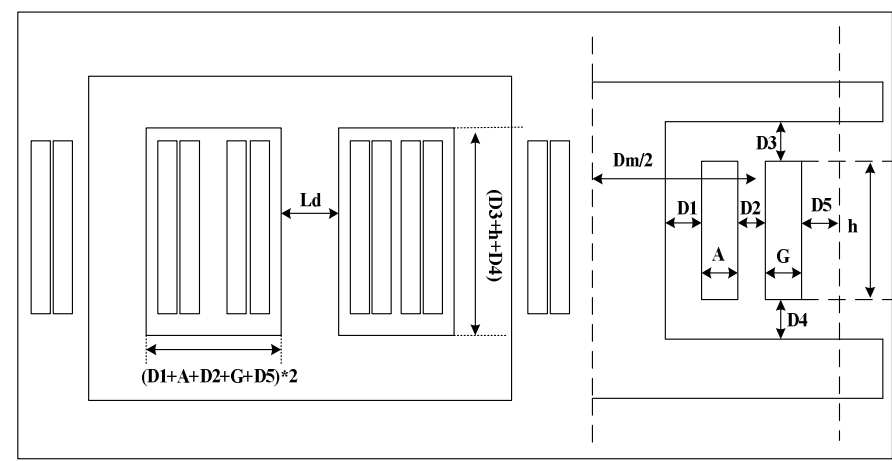

Fig. 1. Geometric dimension of the two-winding three-legged, three-phase transformer

\section{Model of losses}

The iron losses are evaluated as follows thanks to a polynomial interpolation given by equation (16):

$$
\begin{aligned}
& \operatorname{losses}_{\text {iron }}\left(\mathrm{B}_{\mathrm{T}}\right)=\left[1.996-8125\left(\mathrm{~B}_{\mathrm{T}}\right)+12.277\left(\mathrm{~B}_{\mathrm{T}}\right)^{2}-\right. \\
& \left.7.502\left(\mathrm{~B}_{\mathrm{T}}\right)^{3}+1.702\left(\mathrm{~B}_{\mathrm{T}}\right)^{4}\right] \mathrm{w} / \mathrm{kg}
\end{aligned}
$$

Thus, Figure 2 shows the ferromagnetic losses [W / kg] dissipated in a stack of sheets determined from the equation (16), for induction values B, varying from 0.7 to $2 \mathrm{~T}, 60 \mathrm{~Hz}$.

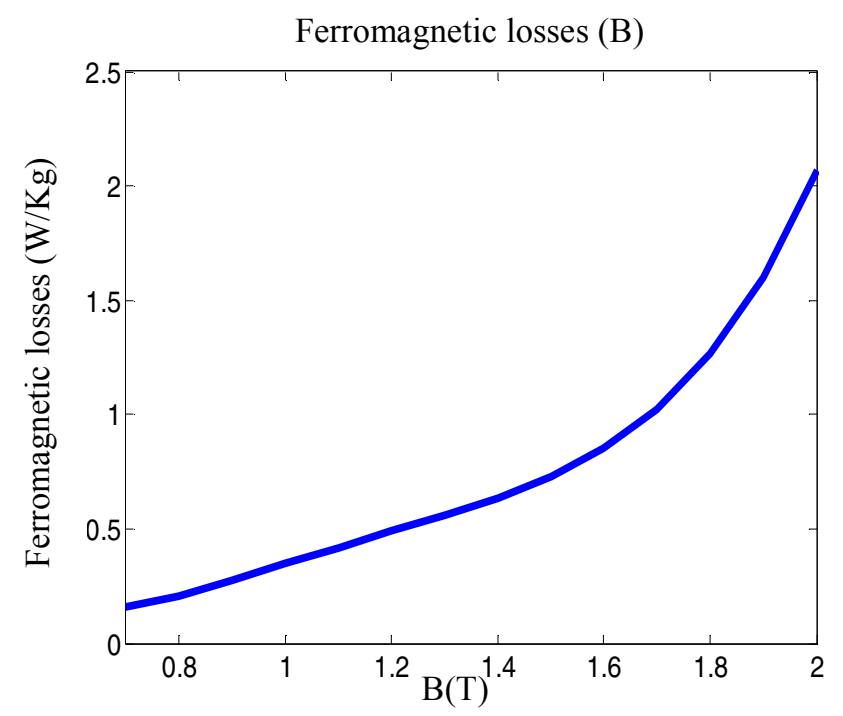

Fig. 2. Ferromagnetic losses

Equation (17) gives the total iron losses of the transformer,

$$
\text { losses }_{\text {iron }}=\text { Mass }_{\text {iron }} \cdot \operatorname{losses}_{\text {iron }}\left(\mathrm{B}_{\mathrm{T}}\right)
$$

As well as equation (18) gives the Copper losses

$$
\begin{aligned}
& \text { losses }_{\text {copper }}=\rho 1 \cdot \mathrm{Vol}_{\text {copper }} \cdot \mathrm{J}^{2} \\
& \text { 4. Transformer Economic model }
\end{aligned}
$$

\section{Transformer Economic model}

The total iron cost is given by equation (9) :

Cost_ $\mathrm{I}=\mathrm{P}_{\mathrm{f}} \mathrm{A}_{\mathrm{L}} \mathrm{F}_{\mathrm{f}} \mathrm{D}_{1}\left[\left(8\left(\mathrm{D}_{1}+\mathrm{A}+\mathrm{D}_{2}+\mathrm{G}+\mathrm{D}_{5}\right)+6 \mathrm{~L}_{\mathrm{D}}+\right.\right.$ $\left.3\left(h+D_{4}+D_{3}\right)\right]$ 
The approximate total cost of copper is given by:

Cost_ $C=3 \pi \mathrm{P}_{\mathrm{c}} \mathrm{D}_{\mathrm{m}} \mathrm{hD_{ \textrm {c } }}\left(\mathrm{AF}_{1}+\mathrm{GF}_{2}\right)$

Equation (21) describes the cost of iron losses

$$
\text { Cost }_{\text {iron-losses }}=\text { losses }_{\text {iron }} \cdot \operatorname{cost}_{\mathrm{kWh}}
$$

Equation (22) describes the cost of copper losses

$$
\text { Cost }_{\text {copper-losses }}=\text { losses }_{\text {copper }} \cdot \operatorname{cost}_{\mathrm{kWh}}
$$

Finally the approximate total cost of transformer is given by:

$$
\text { Cost }_{\text {Tot }}=\text { Cost }_{\text {Tot_losses }}+\text { Cost }_{\text {iron_copper }}
$$

\section{B. Multiple designs Algorithme}

This section describes a conventional methodology for solution of the transformer design optimization problem. This technique assigns many alternative values to the design variables to generate a large number of alternative designs and finally to select the design that satisfies all the problem constraints with minimum manufacturing cost.

There are three design variables:

1. N1-The number of turns of the primary winding

2. B-The magnetic Density

\section{J-Current Density}

The search algorithm of the optimum transformer design is presented in figure (3)

Initialization
Initialize physical constants
Initialize customer specifications
Initialize the constraints
Initialize design variables
For $\mathrm{i}=1$ to dn
For $\mathrm{j}=1$ to db
For $\mathrm{k}=1$ to dj
Calculate the width of core leg
Calculate the height of the column
Calculate the radial thickness of the primary and
secondary winding
Calculate the average diameter of the coils
Calculate the surface of a column
Calculate the volumes densities
Calculate the losses
Calculate the cost of materials (copper and iron)
Calculate the cost losses
Calculate the updated cost of losses over 30 years
Calculate the total cost of the transformer
The optimum transformer is the one with the minimum
manufacturing cost.
End k
End $\mathrm{j}$
End i

Fig. 3. Transformer conventional design algorithm

\section{MultileVEl ANT Algorithm}

This kind of algorithm was designed at the beginning, to solve the travelling salesman problem (Dorigo, 1992).

Since, modifications of such an algorithm, have been made imposing the path of ants at different levels.

The proposed solution to the transformer design optimization problem is described in Fig. 4.

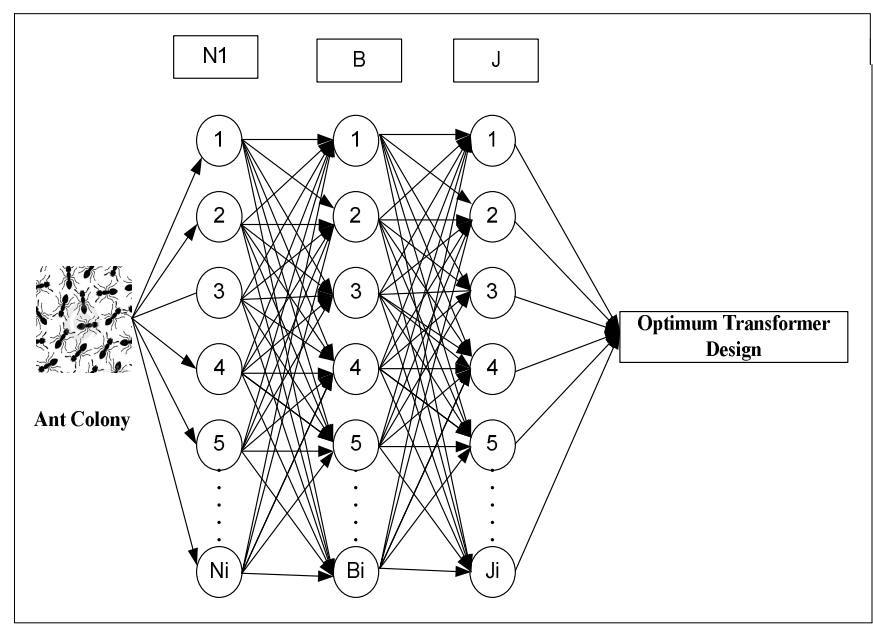

Fig. 4. Flowchart illustrating the main steps of the proposed method

The multilevel ant algorithm is a new approach to solve several optimization problems. Until now, the transformer design optimization problems have been approached by classical, conventional methods only. The aim of the present study is to try to apply the ACO method to such problems. It is based on collective work of ants that can be bserved in ant colonies.

The multilevel ant algorithm (MAA), which is described in Fig. 5, operates as follows.

To accelerate the optimization process, we divide the adjacent states of the problem to several levels; each node contains different value of an optimization parameter.

Ants work synchronously from one level to another by keeping in mind the value of each visited node and depositing pheromone on each path, the probability of going from node $i$ to node $j$ is given by equation (24) :

$$
P_{i j}^{k}=\left\{\begin{array}{c}
\frac{\tau_{i j}^{\alpha}(t)+\eta_{i j}^{\beta}}{\sum_{c_{i j \in N\left(S^{p}\right)}} \tau_{i j}^{\alpha}(t)+n_{i j}^{\beta}}, \text { if } c_{i j} \in N\left(S^{p}\right) \\
0, \text { otherwise }
\end{array}\right.
$$

The visibility $\eta_{i j}$ of each path to the next nodes is defined by the inverse of the distance between the nodes given by

$$
\eta_{\mathrm{ij}}=\frac{1}{\mathrm{~d}_{\mathrm{ij}}}
$$

More elite path that gives the best solution provides the most amount of pheromone $\tau_{i j}$ associated with the edge joining nodes $i$ to $j$, is updated as follows: 


$$
\tau_{i j}(t+1)=(1-\rho) \cdot \tau_{i j}(t)+\sum_{m=1}^{k} \Delta \tau_{i j}^{k}(t)
$$

Where the quantity of pheromone laid on edge $(i, j)$ by ant $\mathrm{k}$

$\Delta \tau_{i j}^{k}(t)=\left\{\begin{array}{r}\frac{Q}{L_{k}(t)}, \text { if ant k use edge }(i, j) \\ 0, \text { otherwise }\end{array}\right.$

The algorithm searches for the best combination of parameters B, N1 and J around the best paths that give optimal transformer with the lowest cost.

The different steps of the mentioned algorithm are summarized in Fig. 5, based on multi-level paths.

Initialize general data of the transformer

Initialize paths with initial amount of pheromone

For $i t=1$ to Maxit (stopping criterion)

For an=1 to NAnts (for each ant)

For $s t=1$ to Nstage-1 (for each level)

Assign a transition probability according to the expression (2.1)

Generate a dimension of a transformer at each iteration for each ant according to the expressions of the geometric model

Calculate for each ant the cost of the transformer according expressions of the Economic Model Update pheromone amounts in all visited paths Find the cheapest path

Increase the pheromone amounts on cheapest path Evaporate pheromone according to the expression (2.3)

end for

end for

end for

Display the best value of design variables and the optimal transformer cost

Fig. 5. Multilevel ant algorithm

\section{RESULTS}

The algorithm was run on a Pentium (R) Dual-Core $2.3 \mathrm{GH}$. Table 1 presents the multilevel ant algorithm parameters.

TABEL I. ANT ALGORITHM PARAMETERS

\begin{tabular}{cc} 
Parameter & Value \\
\hline Number of ant K & 40 \\
\hline Evaporation rate & 0.5 \\
\hline$\alpha$ & 2 \\
\hline$\beta$ & 0.5
\end{tabular}

The performed method is applied to a transformer which specified parameters are as follows, as expected by the customer: Two-winding three-legged, three-phase transformer, primary star-connected, Table 2 shows all the parameters required by the customer:

TABEL II. TRANSFORMER SPECIFIED PARAMETERS

\begin{tabular}{|l|l|}
\hline \multicolumn{1}{|c|}{ Parameter } & \multicolumn{1}{c|}{ Value } \\
\hline Apparent power per phase & St: 40e6 VA \\
\hline Primary voltage & $\mathrm{U} 1: 60 \mathrm{e} 3 \mathrm{~V}$ \\
\hline Frequency & $\mathrm{f}: 50 \mathrm{HZ}$ \\
\hline The percent reactance & $8 \%$ \\
\hline
\end{tabular}

Figure 6 and 7 shows the cost curves of the transformer by iteration.

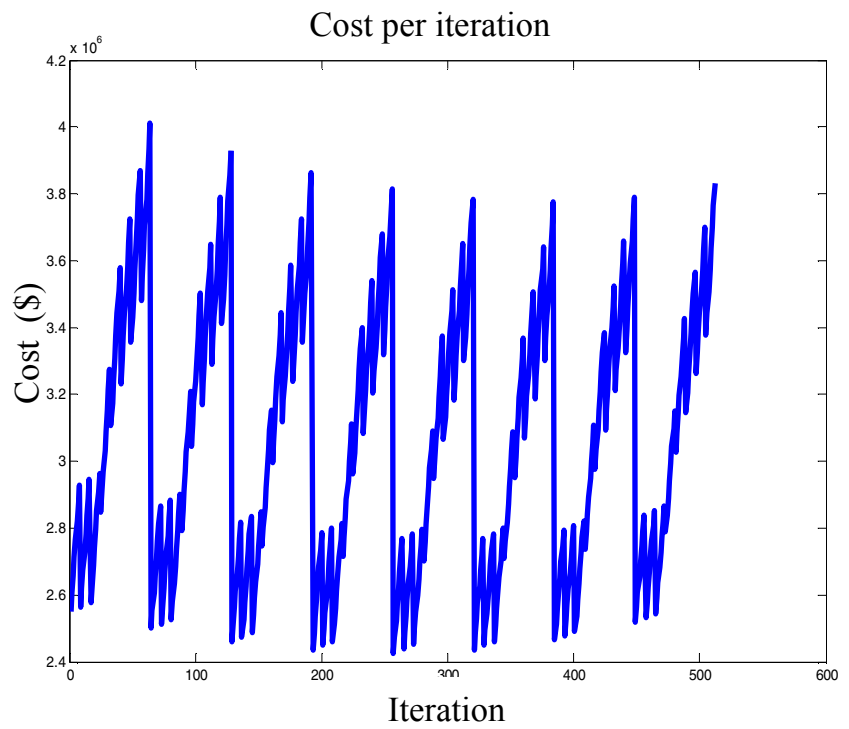

Fig. 6. Cost per iteration with conventional transformer design algorithm

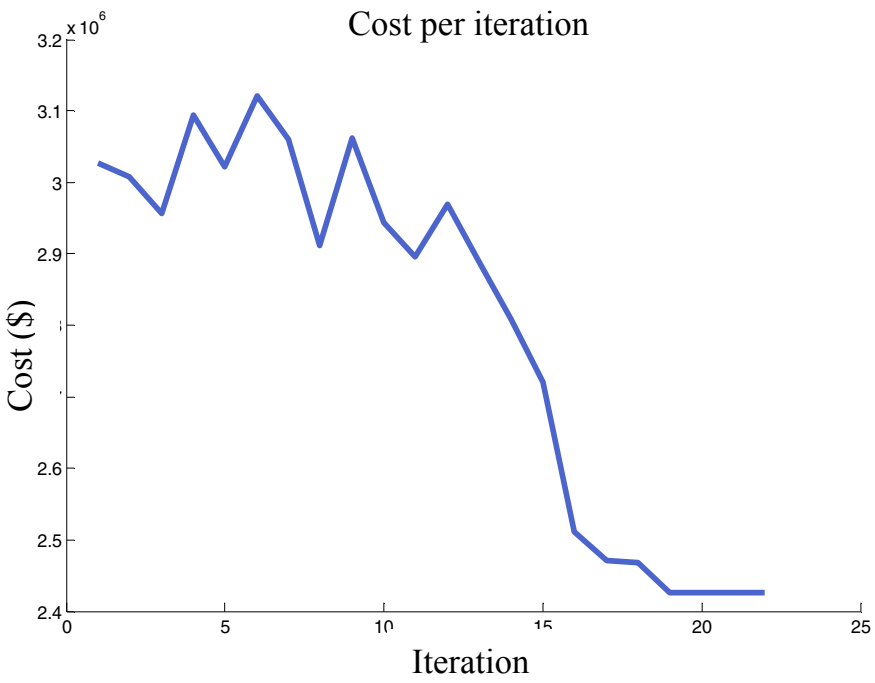

Fig. 7. Cost per iteration with Multilevel Ant Algorithm 
Ant optimal path between levels

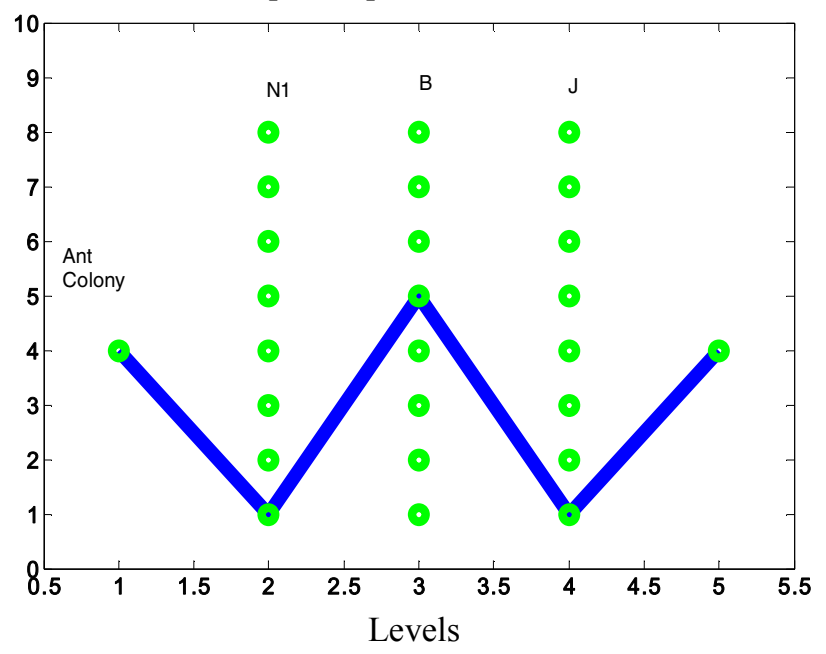

Fig. 8. The Ants optimal path between levels

The results of the two algorithms are shown in Table 3

TABLE III. ALGORITHM RESULT COMPARISON

\begin{tabular}{|c|c|c|}
\hline & $\begin{array}{c}\text { Conventional } \\
\text { transformer } \\
\text { design }\end{array}$ & $\begin{array}{c}\text { Multilevel ant } \\
\text { algorithm }\end{array}$ \\
\hline N1 (n turns ) & 490 & 490 \\
\hline B (T) & 1.8 & 1.8 \\
\hline J( A/mm m $^{2}$ & $3.7 \mathrm{e} 6$ & $3.7 \mathrm{e} 6$ \\
\hline $\begin{array}{c}\text { Success rate on } \\
\text { optimal transformer }\end{array}$ & $100 \%$ & $89 \%$ \\
\hline Time (s) & 0,568 & 0,449 \\
\hline $\begin{array}{c}\text { Time improvement } \\
\text { with Multilevel ant } \\
\text { algorithm }\end{array}$ & \multicolumn{2}{|c}{$20,96 \%$} \\
\hline
\end{tabular}

In the case of the conventional transformer design algorithm convergence to the best solution after 512 iterations but with the multilevel ant algorithm it converges after 19 iterations and saving up to $21 \%$ of time.

\section{CONCLUSION}

The paper here presented, compares a classical method for optimal transformer design based on electromagnetic calculation, to a new optimization technique based on Ant Colony Algorithm. It is adapted to this purpose, proving its good performances. The optimal result is reached with better performance in term of speed. This approach increases converging and improves solution quality. This research is meaningful for popularization and application of ACO method to electrical machines optimal design in general.

\section{REFERENCES}

[1] Marco Dorigo and Thomas Stützle, Ant Colony Optimization, A Bradford Book 2004.
[2] S. sumathi surekha, "Computational Intelligence Paradigms Theory and Applications using Matlab", A Chapman \& Hall Book2010.

[3] M. Poloujadoff, R. D. Findlay,"A Procedure for Illustrating the Effect of Variation of Parameters on Optimal Transformer Design", IEEE Trans. on Power Systems, Vol. PWRS-1, No. 4, pp. 202-205, Nov. 1986.

[4] E.I. Amoiralis, M.A. Tsili, and P.S. Georgilakis, "The state of the Art in Engineering Methods for Transformer Design and Optimization", a survey, Journal of Optoelectronics and Advanced Materials Vol. 10, No. 5, pp. $1149-1158$, May 2008.

[5] N. Monmarché, "Algorithmes de Fourmis Artificielles: Application à la Classification et à l'optimisation", Doctorat Theses Survey, pp. 15 - 45, University of Tours, France, December 2000.

[6] P.S. Georgilakis, N.D. Hatziargyriou, N.D. Doulamis, A.D. Doulamis, and S.D. Kollias "Prediction of Iron Losses of Wound Tansformers Based on Artificial Neural Networks", Elsevier Science Journal - Neurocomputing23, pp. 15-19, July 1998.

\section{NOMENCLATURE}

$\begin{array}{ll}\mathrm{A}, \mathrm{G}, \mathrm{D}_{1} \ldots \mathrm{D}_{5} & \text { Length parameters defined in figure } 1 \\ \mathrm{D}_{\mathrm{m}} & \text { Average turn diameter } \\ \mathrm{f} & \text { Frequency } \\ \mathrm{F}_{\mathrm{f}} & \text { Form factor defining the reactance } \\ \mathrm{F}_{1}, \mathrm{~F}_{2} & \text { Fill factor of copper } \\ \mathrm{h} & \text { Coil height } \\ \mathrm{K} & \text { Ratio of yoke to leg cross section area } \\ \mathrm{A}_{\mathrm{L}} & \text { Leg cross section area } \\ \mathrm{L}_{\mathrm{D}} & \text { Leg diameter } \\ \mathrm{N}_{1} & \text { Number of turns of high voltage winding } \\ \mathrm{P}_{\mathrm{f}}, \mathrm{P}_{\mathrm{c}} & \text { Initial cost of iron and copper } \\ \mathrm{J} & \text { Current density } \\ \rho 1 & \text { Electrical resistivity of copper } \\ \mathrm{S} & \text { Apparent power per leg } \\ \mathrm{V}_{1}, \mathrm{~V}_{2} & \text { High and low voltages (per coil) } \\ \mathrm{X}_{2} & \text { Reactance in \% } \\ \mu_{0} & \text { Empty space permeability } \\ \mathrm{cost} & \text { Cost of energy per Kilowatt-Hour in } \$ \\ \mathrm{k} & \text { Number of ant } \\ \eta_{\mathrm{ij}} & \text { Visibility of next nodes } \\ \mathrm{d}_{\mathrm{ij}} & \text { Distance between the nodes } \\ \tau_{\mathrm{ij}} & \text { Pheromone update pointed by (i,j) } \\ \mathrm{P}_{\mathrm{ij}}^{\mathrm{k}} & \text { The probability of going from node } \mathrm{i} \text { to } \mathrm{j} \\ \mathrm{S}^{\mathrm{p}} & \text { Partial solution constructed by ant } \mathrm{k} \\ \alpha & \text { Pheromone preference parameter } \\ \beta & \text { Heuristic preference parameter } \\ \rho & \text { Evaporation rate } \\ \Delta \tau_{\mathrm{ij}}^{\mathrm{k}} & \text { Quantity of pheromone laid on edge (i, j) } \\ \mathrm{L}_{\mathrm{k}} & \text { Weight of the edge constructed by ant } \mathrm{k} \\ \mathrm{Q} & \text { Constant for pheromone update } \\ & \end{array}$

